\title{
Deficits in sensory-specific devaluation task performance following genetic deletions of cannabinoid $(\mathrm{CB} 1)$ receptor
}

\author{
Hans S. Crombag, ${ }^{1,3,4}$ Alexander W. Johnson, ${ }^{1}$ Anne M. Zimmer, ${ }^{2}$ Andreas Zimmer, ${ }^{2}$ \\ and Peter C. Holland ${ }^{1}$ \\ ${ }^{1}$ Neurogenetics and Behavior Center, Department of Psychological \& Brain Sciences, The Johns Hopkins University, Baltimore, \\ Maryland 21218, USA; ${ }^{2}$ Department of Molecular Psychiatry, University of Bonn, 53125 Bonn, Germany
}

\begin{abstract}
Cannabinoid CB1 receptor is abundantly expressed throughout the CNS and is implicated in numerous physiological and behavioral functions, including appetite and feeding. In the present study, wild-type and CBl heterozygous and homozygous knockout mice were tested on an instrumental outcome-selective devaluation task to assess changes in acquired instrumental response levels for a distinct food reward following selective satiation. Deletion of CB1 receptor, as well as reduction in CB1 expression (HET), produced deficits in outcome-selective instrumental devaluation. These results identify a critical role for $C B 1$ receptor in the ability of animals to represent, update, and/or use sensory-specific outcome representations to alter appetitive behaviors.
\end{abstract}

Cannabinoid CB1 receptor (CB1R), a G-protein-coupled receptor, is widely expressed throughout the mammalian CNS, including in forebrain regions such as the striatum, prefrontal cortex, hippocampus, and amygdala (Herkenham et al. 1990; Mailleux et al. 1992; Mailleux and Vanderhaeghen 1992; Arnold et al. 2001). Within these areas, the principal effect of CB1R activation is to modulate synaptic release of other neurotransmitter systems, including opioid, dopamine, glutamate, and GABA, by acting as retrograde synaptic messenger (for review, see Wilson and Nicoll 2002). Consistent with its ubiquitous expression pattern and broad neurochemical action, CB1R modulates a wide range of physiological and behavioral functions, including learning, memory, and emotional and motivational processes.

The role of CB1R function in regulating appetite and feeding has received a great deal of attention (for review, see Kirkham and Williams 2001, 2004). For instance, the CB1 antagonist SR141716A (Rimonabant) or the CB1 inverse agonist AM251 reduces instrumental responding and consumption of food (e.g., Freedland et al. 2000; Thornton-Jones et al. 2005). Additionally, CB1 knockout mice show reduced instrumental responding for food reinforcement and are hypophagic and overall leaner than are wild-type (WT) cohorts (e.g., Ravinet Trillou et al. 2004; Sanchis-Segura et al. 2004). One possible mechanism by which CB1R modulates appetite and consumption may involve modulating the sensory/hedonic impact of palatable food rewards (e.g., Simiand et al. 1998; Mahler et al. 2007; DiPatrizio and Simansky 2008; but see Thornton-Jones et al. 2007). Additionally, CB1dependent changes in food-directed appetitive behaviors may reflect more general changes in reward-learning processes, including those whereby (incentive) value is assigned to instrumental outcomes and/or outcome-associated stimuli (e.g., Holland and Rescorla 1975; Dickinson and Balleine 1995).

\footnotetext{
${ }^{3}$ Present address: Behavioural and Clinical Neuroscience Research Group, School of Psychology, The University of Sussex, Brighton, Falmer, East Sussex, BN1 9QG, UK. ${ }^{4}$ Corresponding author.

E-mail h.crombag@sussex.ac.uk; fax 44-1273-678058.
}

Article is online at http://www.learnmem.org/cgi/doi/10.1101//m.1610510.
The present study was designed to explore the role of CB1R in a task that combines modulation of the impact of palatable food rewards and aspects of incentive learning. WT, CB1 homozygous $(\mathrm{KO})$, and heterozygous (HET) mice were trained on a sensoryselective reinforcer devaluation task (Adams and Dickinson 1981; Colwill and Rescorla 1985; Balleine and Dickinson 1998). This task assesses the ability of animals to represent sensory-specific incentive properties of reinforcers, to update those representations when new information is acquired, and/or to use those updated representations to guide learned behavior (Pickens and Holland 2004; Burke et al. 2008).

CB1 mutant mice were generated according to the method described by Zimmer et al. (1999). Mice were transported from the University of Bonn to Johns Hopkins University and out-bred for one generation to commercially obtained C57BL/6J mice (The Jackson Laboratories, Bar Harbor, ME). Next, heterozygote offspring were mated to produce the WT $(n=8)$, HET $(n=8)$, and KO $(n=7)$ mice that were used in the experiment. Tail-samples were collected, and DNA was isolated and genotyped using standard lysis-buffer and PCR protocols. Mice were housed in groups of four to five littermates in a temperature- and climate-controlled animal facility. Water was available at all times, and food was freely available up to $1 \mathrm{wk}$ prior to the beginning of behavioral training. Starting 1 wk prior to testing, and for the duration of the experiment, mice were food restricted to maintain them at $\sim 90 \%$ of their free-feeding weight. All mice were between 3 and 6 mo of age at the start of testing.

The mice were trained and tested in one of eight conditioning chambers $(21.6 \mathrm{~cm}$ length $\times 17.8 \mathrm{~cm}$ width $\times 12.7 \mathrm{~cm}$ height $)$ with a clear polycarbonate ceiling, front and back walls, aluminum sides, and a floor consisting of stainless steel rods (Med Associates Inc.). The chambers were located inside sound attenuating enclosures and contained a fan that provided ventilation and low-level background noise $(\sim 75 \mathrm{~dB})$, and an incandescent light that provided low-level ( 200 Lux) white illumination. Each chamber was equipped with a custom-built liquid dispensing mechanism, allowing delivery of multiple liquid solutions into a single recessed liquid well. A vacuum-based drainage system allowed for programmed removal of liquid reward. Infrared 
photocells placed inside the receptacle detected head-entries into the liquid-reward receptacle. Two retractable levers (Med Associates Inc.) were placed at $5 \mathrm{~cm}$ distance on either side of the liquidreward receptacle.

Mice were first trained on two 40-min sessions to approach the receptacle and consume one of two solutions, delivered on a random-time 30-sec schedule, which served as rewards. The rewards were a $0.1 \mathrm{~mL}$ orange-flavored sucrose solution or a $0.1 \mathrm{~mL}$ grape-flavored sucrose solution made using $0.1 \%$ Kool-Aid brand flavorings in $10 \%$ sucrose $(\mathrm{w} / \mathrm{v})$. Next, mice were trained to instrumentally respond on levers to receive delivery of the rewards. Two instrumental training sessions per day were conducted separated by a minimum of $2 \mathrm{~h}$. Only one lever was present on each session such that on one session only the left lever was present and on the other only the right lever was present (order of the sessions alternated daily). For half the mice in each genotype group, left lever responses delivered the orange-flavored sucrose and right lever responses delivered the grape-flavored sucrose, and for the remaining mice, the response-outcome contingencies were reversed. On the first day, mice were given 45 -min sessions of each lever-flavor combination, on a fixed-ratio (FR) 1 schedule of reinforcement. Subsequently, the session length was $20 \mathrm{~min}$, and reward was delivered on a random ratio (RR) 5 (days 2-4) or RR10 (days 5-11) schedule. Because many mice (three WT, four HET, and four KO) initially failed to show robust responding on the RR5 schedule, between sessions 3 and 4, these mice underwent a single overnight training period consisting of eight 1-h sessions (four sessions for each lever-flavor combination), separated by 1-h intervals, during which reward was again delivered on an FR1 schedule. No group differences were apparent during the overnight training period.

As is evident from Figure 1, whereas all three genotype conditions rapidly learned to lever-press for both flavored sucrose solutions, response levels and the rate of acquisition were altered as a function of genotype. Thus, as expected from previous reports (Sanchis-Segura et al. 2004), we found that overall lever-press levels for both reinforcers were somewhat attenuated in CB1 KOs, relative to WT but not HET mice. Importantly, no genotype differences in responding for the to-be devalued vs. non-devalued reinforcers were evident.
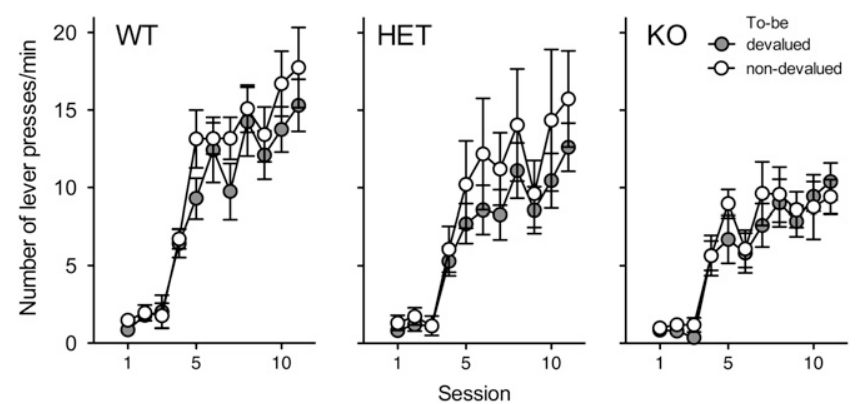

Figure 1. Acquisition of instrumental lever responding in WT, HET, and KO mice for the (to-be) devalued and non-devalued sucrose solutions. Mean ( \pm SE) number of lever presses per minute as a function of session number and schedule of reinforcement (FR1, RR5, or RR10). In all three genotype conditions, mice increased lever responding as a function of training experience (sessions 1-11) and/or instrumental schedule of reinforcement (FR1, RR5, and RR10) $\left(F_{(10,11)}=23.2, P<0.0001\right)$. Three-way ANOVA yielded a significant main effect of genotype $\left(F_{(1,20)}=\right.$ $3.6, P<0.05)$ and genotype $\times$ session interaction effect $\left(F_{(20,200)}=1.94\right.$, $P<0.05$ ). Relative to WT (but not HET) mice, CB1 knockouts showed attenuated instrumental responding for both reinforcers $(P<0.05)$. No significant differences were seen in lever response levels for the to-be devalued and non-devalued reinforcers for any of the genotype conditions (main or interaction effects of lever, Ps $>0.16$ ).
Following instrumental training, mice underwent a sensoryspecific devaluation treatment by prefeeding each mouse with one of the two flavored outcomes for a 2 -h period. Each mouse was placed in a separate housing cage, with a cube-shaped reservoir filled with $2 \mathrm{~mL}$ of either orange- or grape-flavored sucrose solution, fully counterbalanced across the previous response-outcome contingencies. The experimenter monitored and recorded reward consumption during this phase. As the solution was consumed, it was replaced in 1-mL increments to ensure continuous reward availability for each mouse during the 2-h period. During this 2-h free-feeding period, all genotype conditions consumed comparable amounts of sucrose (mean $\pm \mathrm{SE} \mathrm{mL}$ consumed was $3.14 \pm 0.22,4.3 \pm 0.15$, and $3.7 \pm 0.1$ for WT, HET, and $\mathrm{KO}$, respectively).

Immediately after this satiation treatment, the mice were given a 20-min test in the conditioning chambers, during which responses were not reinforced with sucrose delivery (i.e., extinction). Both levers were available during the session for devaluation. To the extent that responding was controlled by the current value of the reward anticipated after each left and right lever press, mice would preferentially perform the response that previously had been reinforced with the reward that had not been prefed, i.e., the non-devalued reward.

As the time-course data in Figure 2A show, all genotypes showed robust responding on both levers and a comparable decline in responding, as would be expected under extinction conditions. However, whereas WT mice showed the expected reduced response rate on the lever associated with the devalued reinforcer, compared with the non-devalued reinforcer lever, HET and $\mathrm{KO}$ mice failed to show such devaluation.

Because the majority of responding during the test occurred within the first $10 \mathrm{~min}$ of the session, the data were compiled and separately analyzed for the first and second halves of the session (Fig. 2B). Analysis of the first $10 \mathrm{~min}$ again showed that WT mice exhibited a selective devaluation effect but CB1 HET and KO mice failed to preferentially respond on the non-devalued reinforcer lever. Indeed, CB1 KOs responded more on the devalued lever than the other genotype groups-a finding similar to previous results following genetic targeting of AMPA GluR1 subunit function (Johnson et al. 2005, 2007), as well as protein synthesis inhibition (Wang et al. 2005) or lesions (Hatfield et al. 1996) of the basolateral amygdala. The second half of the test session (10-20 min) showed no differences. Interestingly, the number of headentries into the reward receptacle (Fig. 2C) also varied with genotype as CB1 KOs showed a higher rate of head-entries into the reward receptacle compared with WT or HET mice.

Finally, we assessed the ability of all mice to discriminate between the devalued and non-devalued solutions per se on a final test session. On completion of a 2 -h prefeeding procedure identical to that used prior to the instrumental test, the mice were given access to two cubes, one containing $2 \mathrm{~mL}$ of the prefed reward and the other containing $2 \mathrm{~mL}$ of the other reward. Mice were given 30 min to consume each reward. As shown in Figure 3, all three genotypes had equal preference on the sucrose consumption test for the non-devalued over the devalued sucrose solution.

Global and constitutive deletion of CB1R resulted in a marked deficit in the ability of mice to use sensory-selective outcome expectancies to modulate instrumental performance. Thus, unlike WTs, CB1 HET and KO mice failed to reduce instrumental response rates for a prefed (devalued) reward, relative to a non-devalued reward. Importantly, this devaluation deficit was not due to a simple deficit in sucrose consumption during the prefeeding period or the ability to detect changes in reward value per se, because HET and KO mice showed normal prefeeding-induced revaluation in consumption. These findings identify a role of CB1R signaling in the representation of sensory and motivational 
A
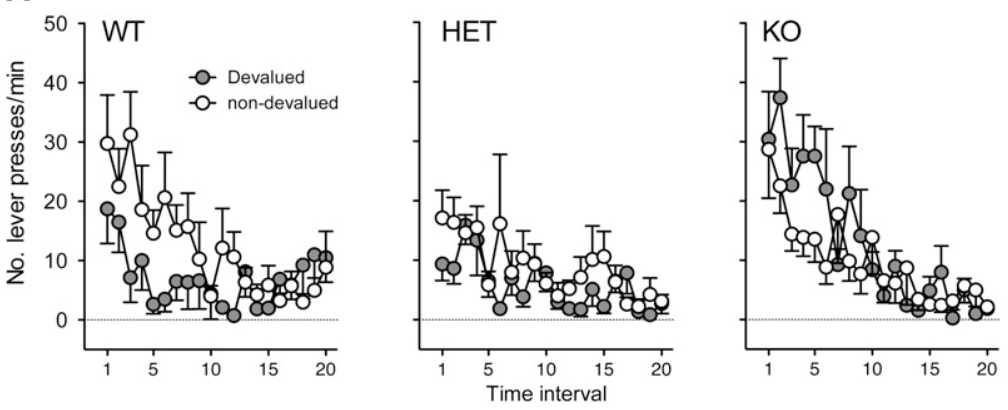

B

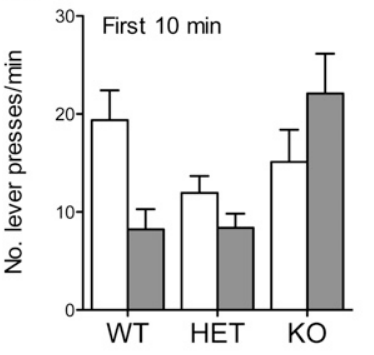

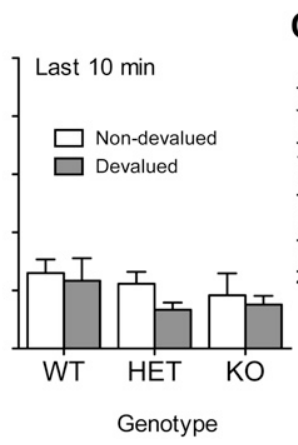

C

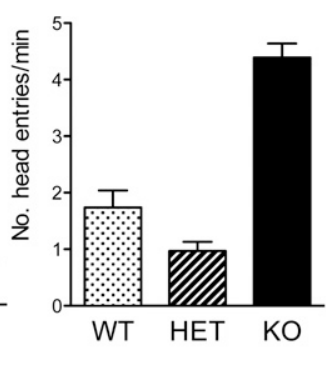

Figure 2. Post-satiation test for outcome-selective devaluation conducted under extinction conditions for WT, HET, and KO mice. ( $A$ ) Mean ( \pm SE) number of presses per minute on the lever associated with the devalued or non-devalued sucrose solutions across the 20 min test session. Three-way ANOVA yielded significant main effects of time $\left(F_{(9,180)}=8.9, P<0.001\right)$, and genotype $\left(F_{(1,20)}=4.7, P<\right.$ $0.05)$, as well as a significant interaction between lever and genotype $\left(F_{(2,180)}=4.5, P<0.05\right)$. $(B)$ Mean ( \pm SE) number of lever presses on the lever previously associated with the devalued or nondevalued sucrose solution averaged for the first and second 10-min halves of the test session. Two-way ANOVA conducted on the data of the first $10 \mathrm{~min}$ yielded a main effect of genotype $\left(F_{(2,20)}=4.5, P<\right.$ $0.05)$, no main effect of lever $\left(F_{(1,20)}=1.5, P=N S\right)$, and a significant interaction effect between genotype and lever $\left(F_{(2,20)}=6.2, P<0.01\right)$. Post-hoc analyses showed significant difference between responding on the devalued vs. non-devalued lever in WT mice $(t=3.2, P<0.05)$, but no such differences were seen in CB1 HET or KO mice. Further analyses also showed that responding to the devalued lever was significantly greater in the KO than in the other genotypes $(t>3.7, P<0.01)$. Analysis of the second half of the test session (10-20 min) yielded no significant main or interaction effects. (C) Mean ( $\pm S E$ ) number of head-entries per minute into the reward receptacle during the test for devaluation. One-way ANOVA showed a significant effect of genotype $\left(F_{(2,20)}=51.8, P<0.0001\right)$ resulting from a markedly higher rate of head-entries into (as well as the amount of time spent inside) (data not shown) the reward receptacle for CB1 KO mice compared with the WT or HET groups ( $t$ s $>$ 7.6, Ps $<0.05)$.

properties of reinforcers and the ability to update those representations when new information is acquired (i.e., revaluation) and/ or to use those updated representations to modify goal-directed behaviors.

Hilario et al. (2007) also reported abnormal sensitivity of lever-pressing to outcome devaluation in CB1 KO and HET mice. However, whereas we report decreased sensitivity to outcomeselective devaluation in CB1 HET and $\mathrm{KO}$ mice, Hilario et al. (2007) reported the opposite pattern. Specifically, using training procedures (interval schedules of reinforcement) (Adams and Dickinson 1981) that produced devaluation-insensitive habit learning in WT mice, CB1 HET and KO mice did show a selective devaluation effect, leading Hilario et al. (2007) to suggest that CB1R signaling was important for habit learning. Although it is difficult to explain these apparent opposite results, and the mice used in both studies were from the same source (Zimmer et al. 1999), a number of procedural differences existed between the two studies. Most notably, whereas the present study used reinforcers that differed only in their sensory (flavor) aspects and mice were trained on two lever-reinforcer contingencies, Hilario et al. (2007) used reinforcers that differed in multiple aspects (including postingestive) and only one action-outcome association was trained.

Clearly, these procedural variations resulted in tasks that engage qualitatively different neural mechanisms that are modulated by CB1 receptor activation. CB1R's broad function as a modulator of various other neurotransmitter systems seems to permit such a view.

Given that CB1R is expressed widely throughout the brain, and both the present and Hilario et al.'s (2007) studies used constitutive, global knockouts, we cannot reasonably speculate about where in the brain CB1R may be involved in modulating the effects of outcome-selective devaluation on instrumental behavior. Nonetheless, previous studies have identified a number of brain regions and circuitries involved in the type of devaluation task used here, including the basolateral amygdala (Hatfield et al. 1996; Blundell et al. 2001; Balleine et al. 2003; Wang et al. 2005; Wellman et al. 2005), the medial dorsal thalamus (Corbit et al. 2003), and the prelimbic region of the prefrontal cortex (Corbit and Balleine 2003). As most of these regions are known to have CB1-modulated inputs or outputs (for recent review, see Maldonado et al. 2006), in the present study, CB1 deletion may have impaired outcome-selective devaluation by interfering with normal function in one or more of these brain regions. Likewise, Hilario et al. (2007) suggested that CB1 deletion interfered with normal activity of brain regions important for habit learning, such as the dorsolateral striatum. Clearly, future studies using region-selective CB1R manipulations across a range of behavioral training procedures are needed.

Despite the widespread expression of CB1R and broad neurochemical consequences of $\mathrm{CB} 1 \mathrm{R}$ activation, $\mathrm{KO}$ mice were mostly "normal" and quantitatively comparable in their behavior to WT mice. Thus, like WT (and HET) mice, CB1 KO mice showed (1) normal post-satiation discrimination and preference on the test for consumption; (2) robust, albeit somewhat attenuated, instrumental response

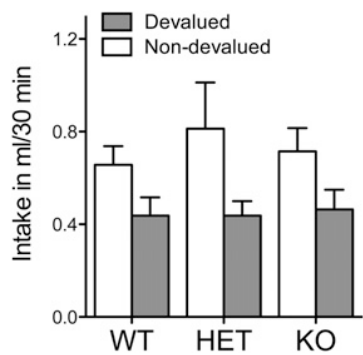

Figure 3. Post-satiation consumption test following selective satiation for WT, HET, and KO mice. Mean ( $\pm \mathrm{SE}$ ) volume (in milliliters) of sucrose consumed following the selective-satiation procedure for WT, HET, and KO mice. Two-way ANOVA yielded a main effect of reward $\left(F_{(1,20)}=\right.$ $7.5, P<0.05)$, but no main or interaction effects of genotype $\left(F_{5}<0.7\right.$, Ps $>0.2$ ). 
rates for sucrose rewards irrespective of flavor; and (3) high overall instrumental response levels and normal extinction rates during the test for devaluation conducted in the absence of reinforcement. In fact, compared with HETs and WTs, CB1 KO mice showed heightened levels of responding on the lever associated with the devalued reward. Interestingly, these mice also showed heightened head-entry responses toward the reward receptacle. It is possible, therefore, that this increased responding toward the reward magazine was, in part, due to the greater lever response levels, as lever presses are frequently followed by magazine responses. Whatever the case, our results clearly indicate that the deficit produced by CB1R deletion is specific to the devaluation task and not the result of more diffuse changes in motivational "state."

It is worth noting that, like CB1 KO mice, the HET group also failed to show a normal devaluation effect (while not differing from WTs during instrumental training or with respect to the number of head-entries during the instrumental devaluation test). In considering this group's performance, Selley et al. (2001) reported that CB1 HET mice show an approximate 50\% reduction in receptor levels in most CB1-expressing brain regions, including striatal and prefrontal areas. On the other hand, these mice were also found to have region-specific increases in receptor-mediated G-protein efficiency, suggesting compensatory mechanisms in response to the decreased receptor levels. From a functional behavioral perspective, therefore, there is no a priori reason to predict that HET mice would be more likely to resemble WT or KO mice. Although the present findings suggest that partial reduction in CB1R-mediated biological function in HETs is sufficient to disrupt performance on a devaluation task, the same partial knockout does not interfere with the ability of Pavlovian conditioned reward-associated cues to serve as reinforcers for instrumental responding (conditioned reinforcement). By contrast, the full $\mathrm{KO}$ produces deficits in both devaluation (present data) and conditioned reinforcement (Crombag et al. 2007).

Because CB1R modulates multiple neurotransmitter systems, there are many possible neurochemical mechanisms by which its deletion might affect devaluation performance. Although an obvious mechanism could be through interactions with mesocorticolimbic dopamine systems, Yin et al. (2006) reported that dopamine transporter (DAT) knockdown mice show normal sensitivity to outcome-devaluation induced by sensory-specific satiety. We have, however, recently found similar deficits in devaluation in mice with genetic deletions targeting glutamatergic function, in particular AMPA receptor function. For instance, in line with earlier results obtained using mice with AMPA-GluR1 subunit mutations (Johnson et al. 2005), the absence of neuronalactivity regulated pentraxins (NARP) - a secreted neuronal product that clusters AMPA receptors-interferes with normal outcomeselective devaluation (Johnson et al. 2007). Taken together with evidence that CB1R activation inhibits excitatory glutamatergic synaptic transmission in various brain regions, including the striatum and ventral tegmental area (e.g., Gerdeman and Lovinger 2001; Melis et al. 2004), as well as the establishment of synaptic plasticity (LTD) at glutamatergic (and GABAergic) synapses (Adermark et al. 2009), CB1R's role in the outcome-selective devaluation reported here could depend on cannabinoid-glutamatergic interactions.

\section{References}

Adams C, Dickinson A. 1981. Instrumental responding following reinforcer devaluation. QJ Exp Psychol B 33: 109-121.

Adermark L, Talani G, Lovinger DM. 2009. Endocannabinoid-dependent plasticity at GABAergic and glutamatergic synapses in the striatum is regulated by synaptic activity. Eur J Neurosci 29: 32-41.
Arnold JC, Topple AN, Mallet PE, Hunt GE, McGregor IS. 2001. The distribution of cannabinoid-induced Fos expression in rat brain: Differences between the Lewis and Wistar strain. Brain Res 921: 240255.

Balleine B, Dickinson A. 1998. The role of incentive learning in instrumental outcome revaluation by specific satiety. Anim Learn Behav 26: $46-59$.

Balleine BW, Killcross AS, Dickinson A. 2003. The effect of lesions of the basolateral amygdala on instrumental conditioning. J Neurosci 23: 666675.

Blundell P, Hall G, Killcross S. 2001. Lesions of the basolateral amygdala disrupt selective aspects of reinforcer representation in rats. J Neurosci 21: 9018-9026.

Burke KA, Franz TM, Miller DN, Schoenbaum G. 2008. The role of the orbitofrontal cortex in the pursuit of happiness and more specific rewards. Nature 454: 340-344.

Colwill RM, Rescorla RA. 1985. Post-conditioning devaluation of a reinforcer affects instrumental responding. J Exp Psychol Anim Behav Process 11: 120-132.

Corbit LH, Balleine BW. 2003. The role of prelimbic cortex in instrumental conditioning. Behav Brain Res 146: 145-157.

Corbit LH, Muir JL, Balleine BW. 2003. Lesions of mediodorsal thalamus and anterior thalamic nuclei produce dissociable effects on instrumental conditioning in rats. Eur J Neurosci 18: 1286-1294.

Crombag HS, Galarce E, Johnson AW, Johnson J, Zimmer A, Zimmer A, Holland P. 2007. Normal Pavlovian modulation of appetitive responding is disrupted in cannabinoid receptor (CB1) knockout mice. In Proceedings of the Thirty-Seventh Annual Meeting of the Society for Neuroscience, San Diego, CA.

Dickinson A, Balleine B. 1995. Motivational control of instrumental action. Curr Dir Psychol Sci 4: 162-167.

DiPatrizio NV, Simansky KJ. 2008. Activating parabrachial cannabinoid CB1 receptors selectively stimulates feeding of palatable foods in rats. J Neurosci 28: 9702-9709.

Freedland CS, Poston JS, Porrino LJ. 2000. Effects of SR141716A, a central cannabinoid receptor antagonist, on food-maintained responding. Pharmacol Biochem Behav 67: 265-270.

Gerdeman G, Lovinger DM. 2001. CB1 cannabinoid receptor inhibits synaptic release of glutamate in rat dorsolateral striatum. J Neurophysiol 85: $468-471$.

Hatfield T, Han JS, Conley M, Gallagher M, Holland P. 1996. Neurotoxic lesions of basolateral, but not central, amygdala interfere with Pavlovian second-order conditioning and reinforcer devaluation effects. J Neurosci 16: 5256-5265.

Herkenham M, Lynn AB, Little MD, Johnson MR, Melvin LS, de Costa BR, Rice KC. 1990. Cannabinoid receptor localization in brain. Proc Natl Acad Sci 87: 1932-1936.

Hilario MR, Clouse E, Yin HH, Costa RM. 2007. Endocannabinoid signaling is critical for habit formation. Front Integr Neurosci 1: 6. doi: 10.3389/ neuro.07.006.2007.

Holland PC, Rescorla RA. 1975. The effect of two ways of devaluing the unconditioned stimulus after first- and second-order appetitive conditioning. I Exp Psychol Anim Behav Process 1: 355-363.

Johnson AW, Bannerman DM, Rawlins NP, Sprengel R, Good MA. 2005. Impaired outcome-specific devaluation of instrumental responding in mice with a targeted deletion of the AMPA receptor glutamate receptor 1 subunit. J Neurosci 25: 2359-2365.

Johnson AW, Crombag HS, Takamiya K, Baraban JM, Holland PC, Huganir RL, Reti IM. 2007. A selective role for neuronal activity regulated pentraxin in the processing of sensory-specific incentive value. J Neurosci 27: 13430-13435.

Kirkham TC, Williams CM. 2001. Endogenous cannabinoids and appetite. Nutr Res Rev 14: 65-86.

Kirkham TC, Williams CM. 2004. Endocannabinoid receptor antagonists: Potential for obesity treatment. Treat Endocrinol 3: 345-360.

Mahler SV, Smith KS, Berridge KC. 2007. Endocannabinoid hedonic hotspot for sensory pleasure: Anandamide in nucleus accumbens shell enhances "liking" of a sweet reward. Neuropsychopharmacology 32: 2267-2278.

Mailleux P, Vanderhaeghen JJ. 1992. Distribution of neuronal cannabinoid receptor in the adult rat brain: A comparative receptor binding radioautography and in situ hybridization histochemistry. Neuroscience 48: $655-668$.

Mailleux P, Parmentier M, Vanderhaeghen JJ. 1992. Distribution of cannabinoid receptor messenger RNA in the human brain: an in situ hybridization histochemistry with oligonucleotides. Neurosci Lett 143: 200-204.

Maldonado R, Valverde O, Berrendero F. 2006. Involvement of the endocannabinoid system in drug addiction. Trends Neurosci 29: 225232 .

Melis M, Pistis M, Perra S, Muntoni AL, Pillolla G, Gessa GL. 2004. Endocannabinoids mediate presynaptic inhibition of glutamatergic 
transmission in rat ventral tegmental area dopamine neurons through activation of CB1 receptors. I Neurosci 24: 53-62.

Pickens CL, Holland PC. 2004. Conditioning and cognition. Neurosci Biobehav Rev 28: 651-661.

Ravinet Trillou C, Delgorge C, Menet C, Arnone M, Soubrie P. 2004. CB1 cannabinoid receptor knockout in mice leads to leanness, resistance to diet-induced obesity and enhanced leptin sensitivity. Int J Obes Relat Metab Disord 28: 640-648.

Sanchis-Segura C, Cline BH, Marsicano G, Lutz B, Spanagel R. 2004. Reduced sensitivity to reward in CB1 knockout mice. Psychopharmacology 176: 223-232.

Selley DE, Rorrer WK, Breivogel CS, Zimmer AM, Zimmer A, Martin BR, SimSelley LJ. 2001. Agonist efficacy and receptor efficiency in heterozygous CB1 knockout mice: Relationship of reduced CB1 receptor density to G-protein activation. J Neurochem 77: 1048-1057.

Simiand J, Keane M, Keane PE, Soubrie P. 1998. SR 141716, a CB1 cannabinoid receptor antagonist, selectively reduces sweet food intake in marmoset. Behav Pharmacol 9: 179-181.

Thornton-Jones ZD, Vickers SP, Clifton PG. 2005. The cannabinoid CB1 receptor antagonist SR141716A reduces appetitive and consummatory responses for food. Psychopharmacology 179: 452-460.
Thornton-Jones ZD, Kennett GA, Vickers SP, Clifton PG. 2007. A comparison of the effects of the $\mathrm{CB}_{1}$ receptor antagonist SR141716A, pre-feeding and changed palatability on the microstructure of ingestive behaviour. Psychopharmacology 193: 1-9.

Wang SH, Ostlund SB, Nader K, Balleine BW. 2005. Consolidation and reconsolidation of incentive learning in the amygdala. J Neurosci 25: 830-835.

Wellman LL, Gale K, Malkova L. 2005. GABAA-mediated inhibition of basolateral amygdala blocks reward devaluation in macaques. J Neurosci 25: $4577-4586$.

Wilson RI, Nicoll RA. 2002. Endocannabinoid signaling in the brain. Science 296: 678-682.

Yin HH, Zhuang X, Balleine BW. 2006. Instrumental learning in hyperdopaminergic mice. Neurobiol Learn Mem 85: 283-288.

Zimmer A, Zimmer AM, Hohmann AG, Herkenham M, Bonner TI. 1999. Increased mortality, hypoactivity, and hypoalgesia in cannabinoid CB1 receptor knockout mice. Proc Natl Acad Sci 96: 5780-5785.

Received August 27, 2009; accepted in revised form October 23, 2009. 


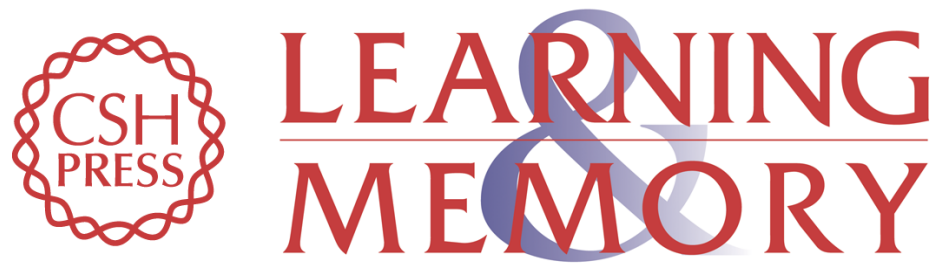

\section{Deficits in sensory-specific devaluation task performance following genetic deletions of cannabinoid (CB1) receptor}

Hans S. Crombag, Alexander W. Johnson, Anne M. Zimmer, et al.

Learn. Mem. 2010, 17:

Access the most recent version at doi:10.1101//m.1610510

References This article cites 39 articles, 12 of which can be accessed free at: http://learnmem.cshlp.org/content/17/1/18.full.html\#ref-list-1

License

Email Alerting Receive free email alerts when new articles cite this article - sign up in the box at the Service top right corner of the article or click here. 